This item was submitted to Loughborough's Research Repository by the author.

Items in Figshare are protected by copyright, with all rights reserved, unless otherwise indicated.

\title{
Multiuse nanopore platform with disposable paper analytical device for the detection of heavy metal ions
}

PLEASE CITE THE PUBLISHED VERSION

https://doi.org/10.1021/acs.iecr.0c04806

\section{PUBLISHER}

American Chemical Society (ACS)

VERSION

AM (Accepted Manuscript)

\section{PUBLISHER STATEMENT}

This document is the Accepted Manuscript version of a Published Work that appeared in final form in Industrial \& Engineering Chemistry Research, copyright @ American Chemical Society after peer review and technical editing by the publisher. To access the final edited and published work see https://doi.org/10.1021/acs.iecr.0c04806.

\section{LICENCE}

CC BY-NC-ND 4.0

\section{REPOSITORY RECORD}

Heaton, Imogen, and Mark Platt. 2020. "Multiuse Nanopore Platform with Disposable Paper Analytical Device for the Detection of Heavy Metal lons". Loughborough University. https://hdl.handle.net/2134/13318133.v1. 
A Multiuse Nanopore Platform with Disposable Paper Analytical Device for the Detection of Heavy Meatal lons

$$
\text { I. Heaton }{ }^{1}, \text { M. Platt }{ }^{*}
$$

1. Department of Chemistry, Loughborough University, Loughborough, Leicestershire. LE11 3TU, UK.

*m.platt@lboro.ac.uk 


\begin{abstract}
The pollution of heavy metal ions within the environmental is a global problem. The rapid and precise removal of these contaminants can be aided by identifying and quantifying the composition of the sample. It is therefore crucial to develop effective portable analytical techniques to determine the levels of heavy metal contamination. Paper-based analytical devices (PADs) offer a low-cost method making them an excellent platform for onsite environmental sensors. Here we demonstrate how a PAD can be integrated into a multi-use Nanopore platform. The PAD was functionalised with different recognition ligands, who's surface charge densities varied in the presence of an analyte. The surface of the PAD was placed in contact with a Nanopore which exhibited Ion Current Rectification (ICR). The extent of ICR, was dependent upon the PAD's surface charge, and the presence of the analyte of interest i.e. the ICR phenomena was exaggerated or diminished indicating the presence of the metal ion in solution.
\end{abstract}

We demonstrate the potential of PAD-ICR using a PAD functionalised with a peptide aptamer specific for nickel ions. Allowing the detection of nickel(II) as low as $0.25 \mu \mathrm{M}$ even in the presence of other metal ions. After any measurement, the Nanopore surface can be wiped clean, and reused. PAD-ICR can also be adapted as a multiplexed sensor. This is demonstrated using a PAD with three different DNA aptamers for simultaneous and specific detection of nickel, mercury, and lead ions. 
Heavy metal ions (HMIs), elements with atomic weights between 63.5 and 200.6, ${ }^{1}$ pose a risk to human health as their non-biodegradable nature can lead to their accumulation in the human body. ${ }^{2}$ Where nickel is considered fundamental in the human body aiding a key role in several enzymes, ${ }^{3}$ when present in higher concentrations, it is known to increase the risk of lung cancer, ${ }^{4}$ dermatitis, ${ }^{5}$ and disorders of the central nervous system. ${ }^{6}$ Accordingly the World Health Organisation, $\mathrm{WHO}$, have placed limits on nickel(II) concentrations acceptable in drinking water, ${ }^{7}$ must be lower than $0.34 \mu \mathrm{M} .{ }^{8}$ With growing human industrial activities such as mining, ${ }^{9}$ metal processing, ${ }^{10}$ and pesticide useage, ${ }^{11}$ there are increasing amounts of HMl's released into the environment.

Traditional analytical methods for the detection of HMls have focused on atomic absorption, ${ }^{12-15}$ and mass spectrometry. ${ }^{16-19}$ Viewed as 'gold standard analytical techniques' due to their sensitivity, reliability and ability to simultaneously analyse multiple elements. ${ }^{20-23}$ However their use can be limited by their high cost of machinery, ${ }^{24}$ expensive operation, ${ }^{25}$ and in cases extensive sample preparation needed. ${ }^{26}$ Alternative techniques have been developed allowing the simple, rapid, onside detection of metal ions. Examples of such sensors include the use of colorimetric, ${ }^{27-29}$ fluorescence, ${ }^{30-33}$ and electrochemical sensors. ${ }^{34,35}$ Paper Based Assays (PADs) are an area of increasing interest due to their low cost, viable mass production, ease of fabrication and modification and ease of disposability. ${ }^{28,36,37}$

Nanopore technologies have also been applied to the detection of metal ions through an array of sensing methods. Biological nanopores record individual binding events between analyte molecules and a single receptor, ${ }^{38}$ and have detected metal ions through the modification of the inner wall of the pore with metal ion recognition sites, ${ }^{39}$ or using DNA/peptides as recognition elements binding with metal ions pre translocation of the nanopore, ${ }^{40-42}$ and even using DNAzymes then monitoring the cleavage products. ${ }^{43}$ Solid State Nanopores (SSNs) have used similar detection mechanisms, ${ }^{44,45}$ and have also been incorporated methods using nanoparticles as carriers for metal ion recognition elements allowing characterisation through changes in carrier speed and/or pulse shape in the presence/absence of metal ions, figure $1 \mathrm{a},{ }^{46-48}$ SSN's are also capable of exhibiting lon Current Rectification (ICR), figure 1b, an asymmetric current-voltage (I-V) response of nanopores when potential bias is applied, also described as non-ohmic behaviour, figures 1c. ${ }^{49,50} \mathrm{ICR}$ in nanopores is 
a result of the electrostatic interactions between the substrate of the nanopore and the electrolyte solution. The surface charge of the nanopore causes ions of the same charge polarity (co-ions) to be depleted from the electrolyte near the nanopore, whereas ions with the opposite charge to the nanopore (counter-ions) accumulate in electrolyte near the nanopore. ${ }^{51-53}$

To the best of our knowledge there has not yet been an assay which utilises a PAD functionalised with recognition elements, which is then "read" by ICR as the signal transduction element. Developing a single sensor for multiple PAD surfaces, that could then also be used for RPS experiments, would allow for the fast, simple qualitative detection of analytes in solution. Previous work within the group has developed the use of a range of recognition elements for heavy metal ions, ${ }^{46-48}$ and herein a peptide aptamer for the detection of nickel was used to develop the assay.

The concept utilises PAD's with different surface charge densities, that when applied directly to the top of the nanopore, affect the accumulation/depletion of ions, which in turn will affect the I-V curve and rectification ratio. To enhance this the inner pore wall was modified with two different polymers, polyacrylic acid-maleic acid (PAAMA), and polyethylene amine (PEI) to achieve a negative and positive coating, respectively. The coating was stable over three days and could be applied quickly, <20 minutes, when required. To demonstrate the ability to measure changes in PAD surface charge, nitrocellulose paper (negatively charged) was applied to nanopores with both inner coatings. The PADs were then functionalised with a peptide and DNA aptamers able to bind to metal ions. The ICR was shown to be specific to the binding of the HMI, the assay was expanded to include different aptamers to allow for the detection of multiple metal ions simultaneously. Using DNA aptamers, the assay was applied to the detection of mercury and lead ions. A PAD was designed with the three different aptamers on to demonstrate the multiplex detection of heavy metal ions 

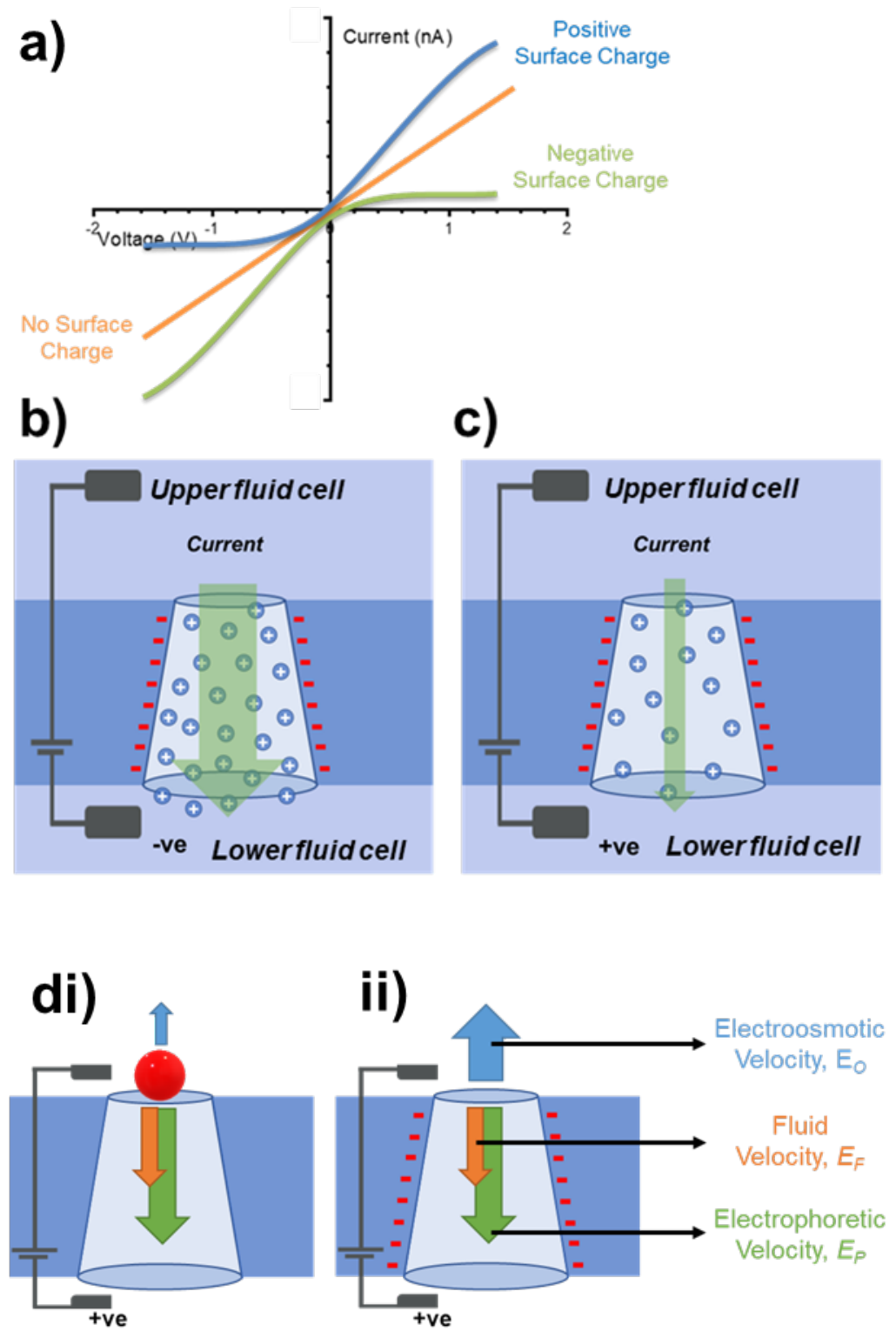

Figure 1: (a) Schematic of the change in current-voltage curve when a pore is coated with a positive and negative surface charge. Schematic of the nanopore after coating with negative charge, (b) with a negative bias applied and (c) with a positive bias applied. (di) Schematic of three forces; electroosmotic, blue, fluid, orange, and electrophoretic, green, acting on a particle as it translocates the pore. (dii) Schematic of how the electroosmotic forces increases with the addition of a negative coating on the inner pore wall. 
Experimental Poly(ethylenimine) (PEl, $\mathrm{M}_{w} 600,000-1,000,000 \mathrm{~g} \mathrm{~mol}^{-1}, 50 \mathrm{wt} \%, 03880$ ), poly(acrylic acid-co-maleic acid) (PAAMA, $\mathrm{M}_{\mathrm{w}} \sim 3,000, \mathrm{~g} \mathrm{~mol}^{-1}, 50 \mathrm{wt} \%, 416053$ ), nickel sulphate hexahydrate (ACS reagent, $99.0 \%, 227676$ ), lead nitrate (ACS reagent, $\geq 99.0 \%, 228621$ ) mercury chloride (ACS reagent, $\geq 99.5 \%, 215465$ ), chromium chloride hexahydrate (reagent, $\geq 98.0 \%, 27096$ ) and iron chloride (reagent grade, $97 \%$, 157740) were purchased from Sigma-Aldrich, UK. Calcium chloride (fused granular, 11488093) and potassium chloride (reagent grade, 1160386) were purchased from Fisher Scientific, UK. Carboxylated polystyrene particles were purchased from Bangs Laboratories US, denoted as CPC200 (mode diameter $210 \mathrm{~nm}$, measured concentration $1 \times 10^{12}$ particles/ $\mathrm{mL}$ ). Nanopores were purchased from Izon Science Ltd NZ, and termed NP200 from the supplier. Reagents were prepared in deionised water (Elga PureLab), with a resistance of $15 \mathrm{M} \Omega \mathrm{cm}$.

Custom peptides and DNA oligonucleotides. Custom peptides were purchased from Mimotopes, Australia, in lyophilised form, minimum purity $96 \%$. They were purified and checked by reverse phase HPLC by the manufacturer. The peptide details are peptide 1; biotin- DTDTDTDTDHHHHHH-OH, peptide with six histidine tag (nickel aptamer), and peptide 2 biotin- DTDTDTDTD-OH, peptide without six histidine tag, and DNA oligonucleotides were purchased from Sigma-Aldrich, in lyophilised form, purified using reverse-phase cartridge purification by the manufacturer. The oligonucleotide ordered was biotin-TTCTTTCTTCGCGTTGTTTGTT-3' (mercury aptamer) and biotin-GGAAGGTGTGGAAGG-3' (lead aptamer). All were diluted to a $100 \mu \mathrm{M}$ stock solution using deionised water.

Nanopore coating. The nanopores were coated by incubating the pore in a polymer solution ( $5 \% \mathrm{w} / \mathrm{v}$ in DI water) at a stretch of $45 \mathrm{~mm}$ for 30 minutes followed by rinsing with DI water and drying.

Particle testing. Carboxylated polystyrene particles were ran through a nanopore before and after coating with PAAMA. NP200s nanopores were used, they can analyse particles from $85-500 \mathrm{~nm}$. More than 200 particles were measured for each sample run. After each measurement was taken the nanopore was cleaned by first rinsing the upper fluid cell with background buffer before the buffer was removed and replaced multiple times each time a different pressure or vacuum was applied. 
PAD functionalisation. Nitrocellulose paper was placed in an avidin solution (1 $\mathrm{mg} / \mathrm{mL}$ in DI water) for minimum 30 minutes, rinsed with DI water before incubation with the peptide aptamer. Finally, they were washed before analysis.

Sample testing. Post incubation with the aptamer the PADs were placed in the test solution for 30 minutes before being rinsed and analysed. Nickel(II) solutions were made up to either $1,0.5$ or $0.25 \mu \mathrm{M}$ with DI water, and the mixture of metal ions were all prepared at $1 \mu \mathrm{M}$. Environmental water samples were collected from a lab tap, an outdoor pond next to the chemistry department, and they were spiked with nickel to make a $1 \mu \mathrm{M}$ solution.

Multiplex testing. To prepare the multiplex PAD a $6 \mathrm{~cm}$ by $1 \mathrm{~cm}$ strip of chromatography paper was cut, and three boxes marked out using pencil. $5 \mu \mathrm{L}$ of avidin solution was dropped into each box and left for 30 minutes to bind, this was repeated with $5 \mu \mathrm{L}$ of the required aptamer and $5 \mu \mathrm{L}$ of the test solutions or DI water (blank).

RPS set up. A qNano (Izon Science Ltd, NZ) was used to complete all the measurements for this study. A qNano uses data capturing software (Izon Control Suite v3.3) to record the particles as they traverse the pore. The lower fluid cell contained $80 \mu \mathrm{L}$ of $\mathrm{KCl}$ solution and the upper fluid cell contained $40 \mu \mathrm{L}$ sample solution. For all experiments an NP200 nanopore was used.

Current-voltage measurements. To ensure a current was established $2 \mu \mathrm{L}$ of $\mathrm{KCl}$ solution was placed on the pore, then the PAD was put on this and finally the upper fluid cell was clipped into place and $40 \mu \mathrm{L} \mathrm{KCl}$ added. The current was then measured at $1.60,1.20,0.80,0.40,-0.40,-0.80,-1.20$ and $-1.60 \mathrm{~V}$, allowing $5 \mathrm{~s}$ for the current to stabilise before the current was recorded. 


\section{Results and Discussion}

The use of ICR within sensing strategies have typically utilised pore diameters that are comparable to the scale to the double layer. ${ }^{51}$ However there are reported examples that break this rule, due to the highly charged surfaces extending ICR to pores of submicron scale. ${ }^{54,55}$ One recent example of a pore that rectifies was polyurethane, PU. These PU pores have been shown to exhibit ICR behaviour even when the pore size is above $400 \mathrm{~nm}$ in diameter. ${ }^{55}$ They are supplied with a conical shape, the narrow end referred to as the pore mouth, with a small negative surface charge, ${ }^{56}$ and reports speculate that the ICR behaviour may arise from cracks, defects within the pore wall structure as opposed to the whole pore volume. ${ }^{54}$ Here the as purchased pores are modified to both enhance the surface charge and charge density. To modify the surfaces the layer-by-layer, LbL, assembly was utilised as previously reported. ${ }^{54}$ For ease of application Poly(ethyleneimine) (PEI), which forms a positive bilayer, and poly(acrylic acid-co-maleic acid) (PAAMA), which forms a negative bilayer, were chosen. To measure the ICR we report the degree of current rectification as the ratio of absolute current recorded at two potentials namely $\pm 1.60 \mathrm{~V},{ }^{54}$ or where needed current-voltage $(\mathrm{I}-\mathrm{V})$ curves were measured by scanning the voltage from $+1.60 \mathrm{~V}$ to $-1.60 \mathrm{~V}$.

Prior to any LbL chemistry, the pore wall possesses a slight negative charge ${ }^{56}$ exhibiting a weak ICR of circa $<1.11$ see figure $1 \mathrm{a}$, after coating with PAAMA or PEI it was possible to measure a stronger ICR response $>2.00$ and $<0.20$ respectively, Figure 1a. Shown in table 1 are the voltages measured at 1.60 and $-1.60 \mathrm{~V}$ for two pores pre and post coating.

\begin{tabular}{|c|c|c|c|c|}
\hline $\begin{array}{c}\text { Applied } \\
\text { Voltage (V) }\end{array}$ & \multicolumn{4}{|c|}{ Current (nA) } \\
\hline & Pre-PAAMA & Post-PAAMA & Pre-PEI & Post-PEI \\
\hline $\mathbf{+ 1 . 6 0}$ & 12.15 & 10.85 & 13.40 & 61.20 \\
\hline $\mathbf{- 1 . 6 0}$ & -13.60 & -41.00 & -14.50 & -8.60 \\
\hline
\end{tabular}

Table 1: The measured currents for two pores at +1.60 and $-1.60 \mathrm{~V}$ pre and post coating with PAAMA or PEI. 
For Resistive Pulse Sensing, RPS, shown in figure 1d, each analyte that translocates the pore produces a pulse referred to as the pulse magnitude, $\Delta i_{p}$, that is related to the volume of the particle. The width or full width half-maximum, FWHM, relates to the velocity of the particle and the frequency of pulses relates to the concentration of nanoparticles. ${ }^{56}$ Studies within RPS have demonstrated how in the absence of convection the velocity can be proportional to the analyte or pore's surface charge. ${ }^{48,57}$ 56 The velocity of the particle is a combination of the electroosmotic flow, EO, and electrophoretic movement, EP, under the influence of an applied electric field, shown in figure $1 \mathrm{~d}$. The velocity of nanoparticles through PU pores have been used to determine their zeta potential. ${ }^{56}$ Modifying the pore with LbL chemistry should result in a change in $\mathrm{EO}$ and a measurable change in translocation velocity of particles. To demonstrate that the LbL had not formed a porous layer blocking the whole pore, 200 $\mathrm{nm}$ particles were passed through the PU membrane, and then again post coating with PAAMA, Figure S1. Although there was a drop in the average particle rate, from 168 to 46 particles per min, the baseline current did not change by more than $10 \%$ indicating no significant change in pore size, the average blockade magnitude only slightly decreased slightly, by less than $10 \%$ across the three runs.

Converting the translocation velocity into a zeta potential is performed by measuring the velocity at a range of voltages, interestingly coating the pore with PAAMA resulted in an enhanced ratio of velocities, Figure $2 \mathrm{~b} .{ }^{56}$ The ratio of particle speeds taken at V1 a high voltage and V3 a low voltage, figure $2 \mathrm{~b}$, suggests this might aide future zeta potential measurements. The average speeds for the particle velocities for each voltage reported in Table S1. The improved ability to differentiate the velocity of particles was not the aim here and RPS is used as an indicator of an open pore. This result also shows that our previous particle-based assays could be added to the PADS assay here as a single platform for a range of sensing applications.

The durability of the PAAMA coating was tested over four days, the coating was shown to have the higher ICR on day one and showed little variation on days two and three before it was no longer able to ICR on day four, Figure S2. 
a)

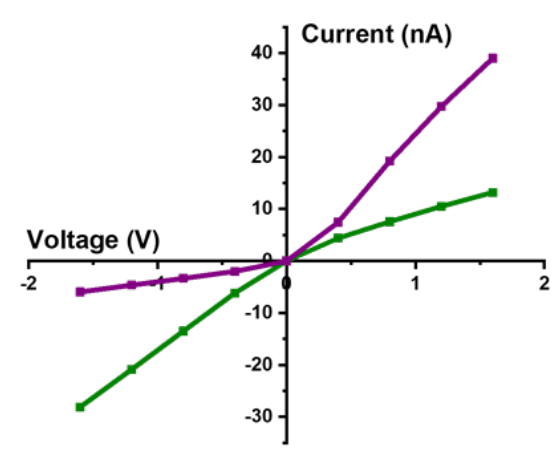

b)

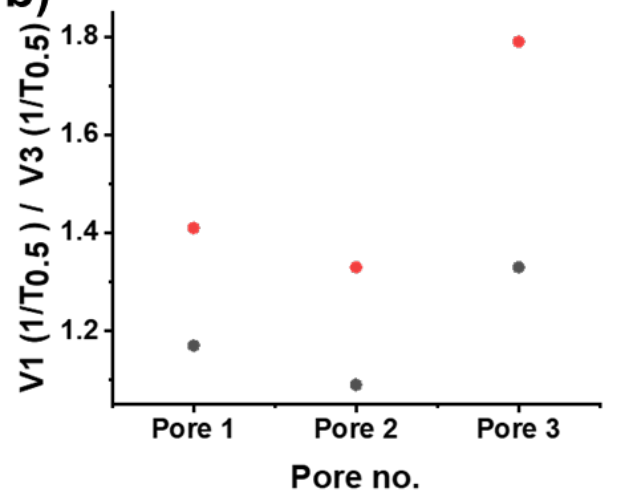

Figure 2: (a) Current-voltage curves of the nanopore coated with PAAMA, green, and $P E I$, purple. (b) Ratio of V1N3 reported for three different nanopores pre, grey, and post, red, modification with PAAMA. Measured in PBS with a $47 \mathrm{~mm}$ stretch and no pressure applied, on the same day with more than 200 particles counted.

One area of ICR which has not been exploited is how external stimuli, e.g. a piece of paper placed on top of the nanopore affects the I-V response. Although a similar mechanism is used in Scanning electrochemical microscopy, ${ }^{58,59}$ the application of a sensing strip to a Nanopore has not been shown for analytical purposes, although we note that placing buffers of different ionic strength and $\mathrm{pH}$ either side of the pore has been explored. ${ }^{60,61}$ Paper Based Assays (PADs) are an area of increasing interest due to their low cost, viable mass production, ease of fabrication and modification and ease of disposability. ${ }^{28,36,37}$ Previous work using ICR to detect metal ions has focused on binding recognition elements to the inner pore walls allowing the selective binding of specific analytes which in turn affect the ionic transport across the nanopore altering the I-V curve seen. ${ }^{54}$ Examples of such recognition elements include aptamers, ${ }^{54,62}$ amino acids, ${ }^{63-65}$ and proteins. ${ }^{66,67}$ However, this limits the number of analytes the system can detect simultaneously and is not a simple system to prepare or regenerate. Such ICR assays have been demonstrated for several different heavy metal ions including mercury, ${ }^{68,69}$ copper, $^{70,71}$ and cobalt. ${ }^{72}$

It was hypothesised that the ICR behaviour of the pore would be strongly influenced by the local chemical environment at the pore mouth i.e. placing a surface, figure $3 a$, of differing ionic strength/ surface charge density on top of the pore, figure $3 \mathrm{~b}$, would change the ICR behaviour. To test this a cellulose strip, with no/little inherent surface charge was placed on top of a PAAMA coated PU pore, shown in figure 3b. Before 
the cell was assembled the pore was filled with $5 \mathrm{mM} \mathrm{KCl}$ and the paper was soaked in the same solution for 15 seconds before being placed on top of the pore. The recorded ICR, figure $3 \mathrm{~d}$ and $\mathrm{e}$, was unchanged from the signal without the chromatography paper. Next a PAD with an inherent negative surface charge, nitrocellulose paper, ${ }^{73}$ was placed on top of the PU pore, figure $3 \mathrm{f}, \mathrm{g}$.

a)
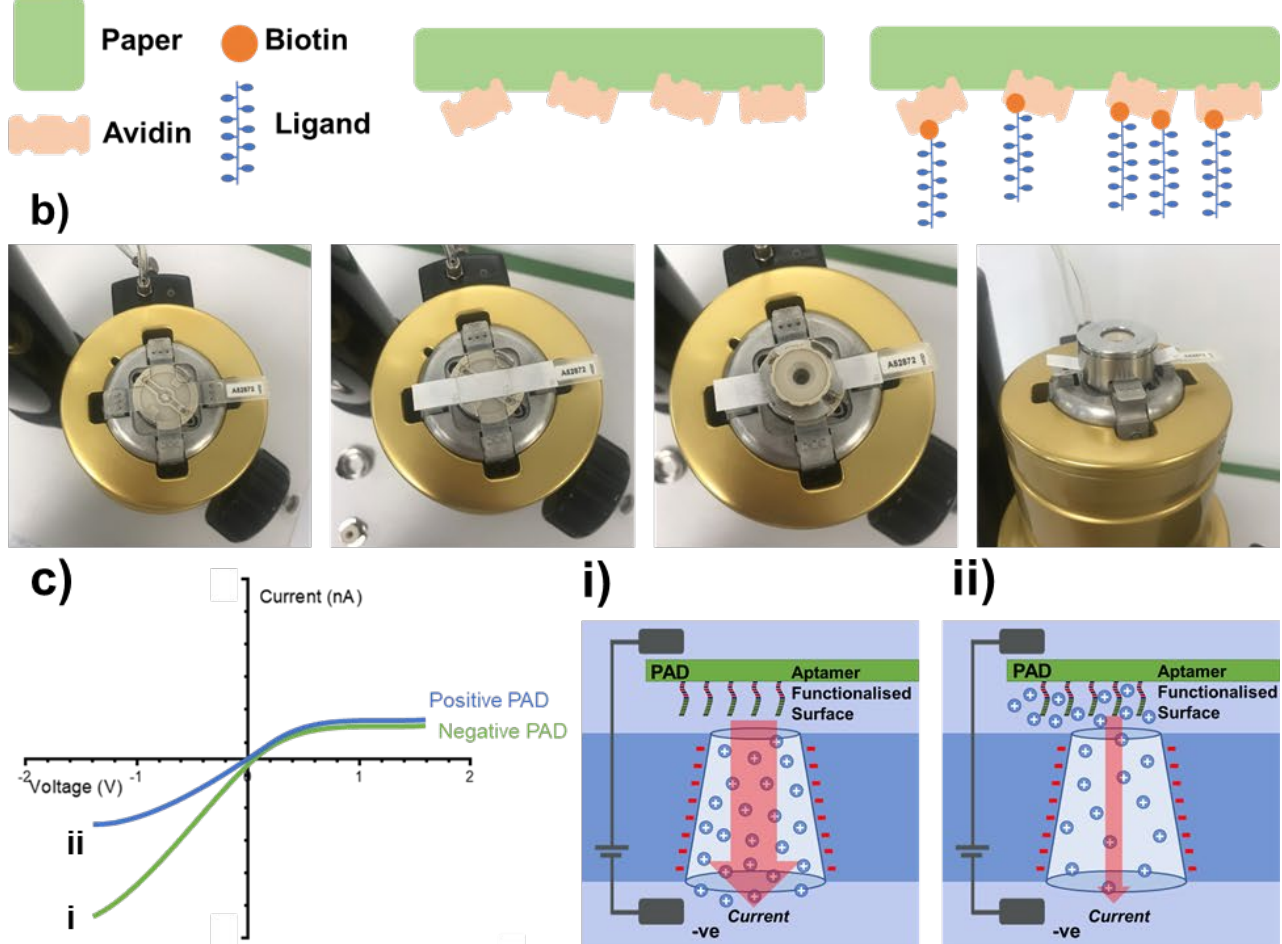

i)

ii)
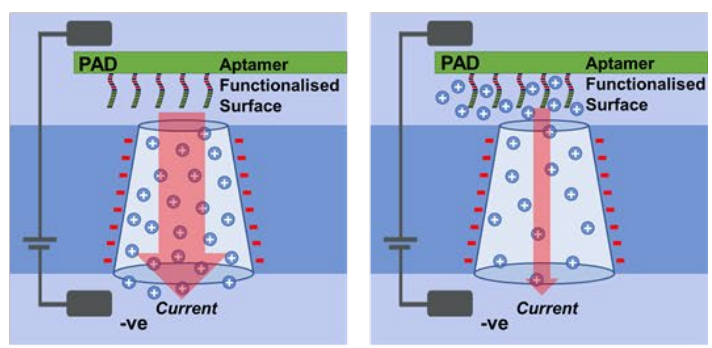

d)

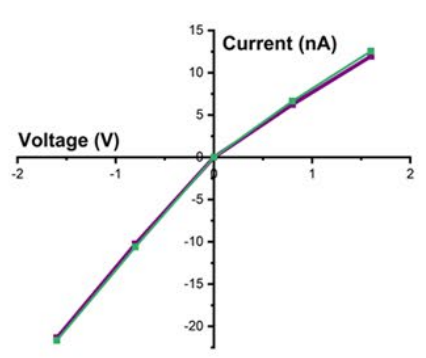

e)

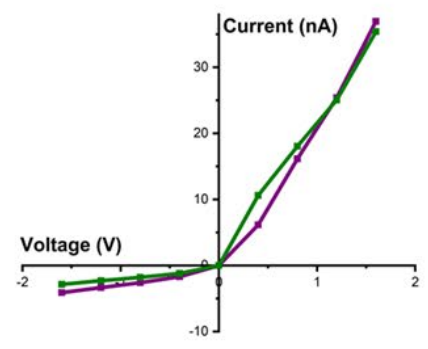

f)

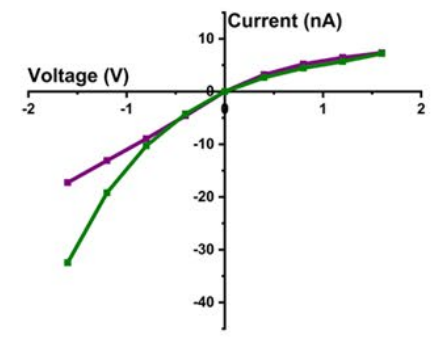

g)

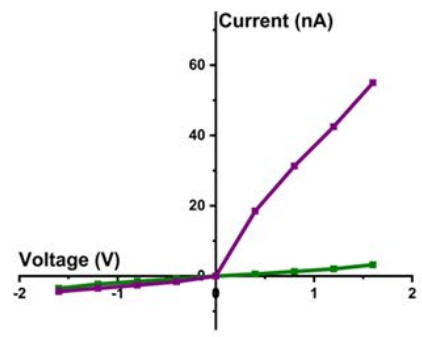


Figure 3: (a) Schematic of avidin binding to the nitrocellulose paper strip before the biotinylated ligand binds with the avidin on the paper surface. (b) Set up of the qNano with a strip of chromatography paper placed on top. (c) Shows the change in currentvoltage curve seen when a positive or negative $P A D$ is place on the pore, schematic of the aptamer functionalised PAD being placed on the pore before (i) and after (ii) binding with target ions. ( $d$ and e) Current-voltage curves of chromatography paper (no inherent charge), soaked with $5 \mathrm{mM} \mathrm{KCl}$, on a nanopore coated with PAAMA (d) and PEI (e). ( $f$ and $g$ ) Current-voltage curves of nitrocellulose paper (negative charge) on a nanopore coated with PAAMA (f) and PEI (g). Blanks, no paper present, purple, and green, paper present. Current-voltage curve data was obtained on NP200s nanopores with $5 \mathrm{mM} \mathrm{KCl} \mathrm{electrolyte}$

When the nitrocellulose paper was placed on a pore modified with PAAMA, the current observed at $-1.60 \mathrm{~V}$ was seen to increase from $-17.25 \mathrm{nA}$, , to $-32.45 \mathrm{nA}$ in the presence of the PAD surface, whilst the current measured at $1.60 \mathrm{~V}$ remained the same, Figure 3f. In contrast when the paper was placed on a pore modified with $\mathrm{PEI}$, the current observed at $-1.60 \mathrm{~V}$ did not change a significant amount from -4.4 to -3.5 , however the current observed at $1.60 \mathrm{~V}$ dropped from 55 to $3.2 \mathrm{nA}$ without and with nitrocellulose paper respectively, Figure $3 \mathrm{~g}$. Repeats of these experiments on the same pore and same day but with different pieces of paper are shown in Figure S3. This confirmed the pores ability to sense the surface chemistry/charges on the papers surface.

Inspired by the change in the ICR response in the presence of different PAD surfaces, the next stage was to incorporate biorecognition elements onto the PADs surface. Utilising the well-known nonspecific binding of proteins to nitrocellulose, avidin was placed onto the nitrocellulose surface, shown schematically in figure $3 a$. This meant the surface could be modified further with biotinylated recognition elements. First we demonstrated this using a peptide aptamer terminating with a six histidine tag, shown to bind to nickel(II) ions. ${ }^{48}$ This aptamer was chosen as the histidine tag holds the nickel(II) ions away from the PAD surface, creating a positive outer layer. ${ }^{48}$

With the system used here it is possible to apply a pressure to the upper fluid cell, forcing the liquid from the upper fluid cell through the pore. In the presence of a PAD, it was hypothesised that the applied pressure would hold the PAD's closer to the pore 
mouth, giving a more reproducible setup and distance between the pore more and PAD surface. A PAD was placed on a pore coated with PAAMA, and the applied pressure was varied from 0 to $15 \mathrm{~cm}$, as shown seen in Figure $S 4$. From 0 to $10 \mathrm{~cm}$ of pressure applied the current was seen to increase from -19.15 to $-24.15 \mathrm{nA}$. after $10 \mathrm{~cm}$ increasing the pressure did not affect the current measured. No significant difference in current was observed above $0 \mathrm{~V}$, indicating that the ICR affect was not diminished due to the addition of pressure.

During the pressure testing the position of the PAD on the PU pore was not moved between I-V curve measurements. To test deviation between I-V curves taken with different PAD positions on the pore an I-V curve was taken three times with the same pore and paper strip, the system was taken apart and the paper moved between each measurement. It was observed that the current observed at $-1.60 \mathrm{~V}$ varied between 25.75 and $-30.9 \mathrm{nA}$, Figure S5. From this we determined that for a result to be considered a significant change the current needed to change by $>5 \mathrm{nA}$.

As previously mentioned, it is known that the histidine peptide aptamer binds with nickel(II) ions in solutions, to test the ability of the assay to measure the binding of nickel(II) to the PAD, PADs functionalised with the peptide aptamer, peptide 1, were incubated in a $1 \mu \mathrm{M}$ nickel(II) solution for 30 minutes. The PAD was then rinsed and placed on the pore, the I-V curved was measured and a significant decrease in the current measured at $-1.60 \mathrm{~V}$, from -21.15 to $-7.1 \mathrm{nA}$ respectively, was recorded, figure 4a. Repeats of these using the same pore but different test strips are shown in the figure S6 and as can be seen the current recorded at $-1.60 \mathrm{~V}$ decreased by more than $5 \mathrm{nA}$ between each test.

To confirm the nickel(II) was binding specifically with the histidine tag a PAD functionalised with a different peptide aptamer, peptide 2, which has no his-tag present on the end was incubated in a $1 \mu \mathrm{M}$ nickel(II) solution for 30 minutes. Here when the PAD was placed on the pore no significant change in the I-V curved was measured for the blank vs. test solution, figure $4 a$. Repeats of these using the same pore but different test strips are shown in the figure S6 and as can be seen the current recorded at $-1.60 \mathrm{~V}$ did not vary by more than $5 \mathrm{nA}$ between each test. 

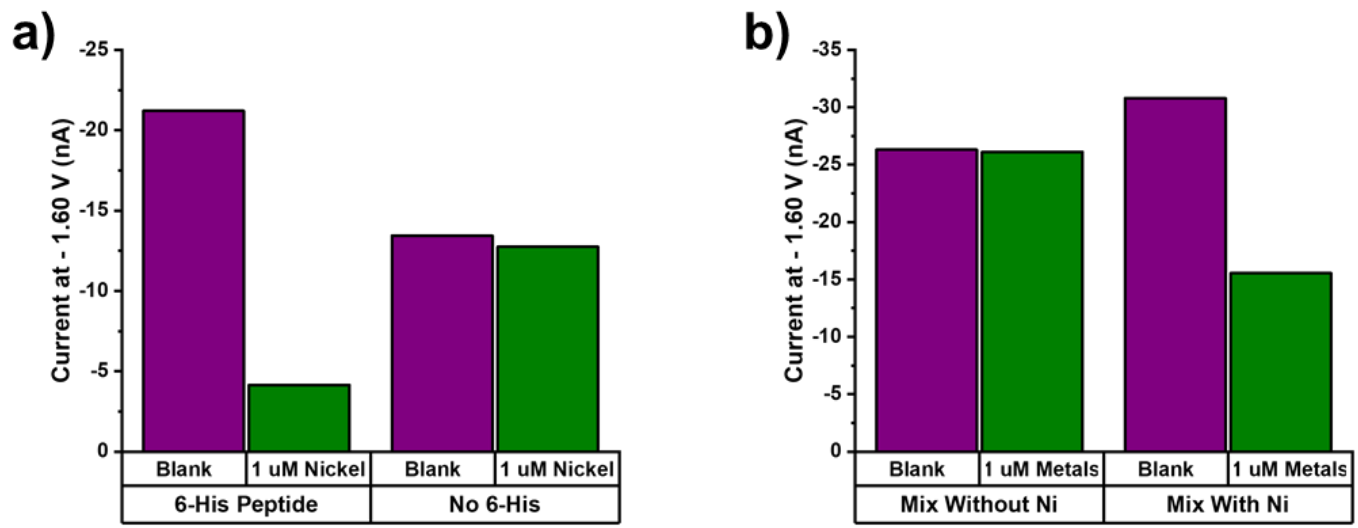

Figure 4: Current observed at $-1.60 \mathrm{~V}$ on a PAAMA coated pore with a PAD functionalised with; (a) peptide aptamer with histidine tag present, and peptide aptamer without the six-histidine tag present, both incubated with, green, and without, purple, $1 \mu \mathrm{M}$ nickel(II). (b) Six-histidine peptide aptamer, incubated with, green and without, purple, a mix containing $1 \mu \mathrm{M}$ calcium(II), chromium(III) and iron(III), and a mix with $1 \mu \mathrm{M}$ nickel(II). All current-voltage curve data was obtained on NP200s nanopores with $5 \mathrm{mM} \mathrm{KCl}$ electrolyte.

To demonstrate the selectivity of the assay to nickel(II) ions, the PAD was incubated with a mix of metal ions; calcium, chromium, and iron, all present at $1 \mu \mathrm{M}$. As shown in Figure $4 \mathrm{~b}$, there was no significant change measured in the I-V curves observed when the other metal ions were present. When nickel(II) ions were added to the mixture, the current measured at $-1.60 \mathrm{~V}$ once again decreased significantly, from 30.8 to $-15.55 \mathrm{nA}$ respectively, Figure $4 \mathrm{~b}$. Repeats of these experiments are shown in Figure 57 .

Due to the current inability to control the density of avidin binding or the Aptamers on the PAD's surface it was not expected to be quantitative assay and would also explain some variation in signal across the surface of the PAD. However, if control over the paper area size, number of avidin binding site and therefore number of aptamers binding we expect that with future work this could be developed into a quantitative assay. This was not considered an issue as this test could be used to indicate the presence of metal ions and if quantification is needed the test solution can be used in a particle assay as previously described. ${ }^{46-48}$ However, as shown in Figure $5 a$ when tested on different pores on different days it was possible to measure nickel(II) concentrations down to $0.25 \mu \mathrm{M}$, which is below the environmentally acceptable limit 
for drinking water.$^{74}$ Repeats on two more pores are shown in Figure S8. Further, as previously demonstrated the pore can still measure particles after coating with PAAMA, so should the PAD indicate the presence of nickel(II) is it possible to measure the quantity of nickel(II) using the previously developed method by simply adding peptide functionalised particles to the sample. ${ }^{48}$

As a demonstration of the assays ability to be used in more complex matrices, environmental water samples were collected. Tap water from the lab tap and pond water from a local pond was collected for testing. Two water samples were taken, one of which was spiked with $1 \mu \mathrm{M}$ nickel(II). PADs were dropped in and incubated for 30 minutes. As can be seen in Figure $5 b$ there was no sample interference observed, with the PADs able to measure a significant decrease in the current measured at -1.60 V. Repeats of these experiments are shown in Figure S9.

Finally, to show the flexibility of the assay the PAD was functionalised with DNA aptamers for lead and mercury. These are known to bind with their respective metals and not suffer from interferences. ${ }^{46}$ The previous RPS assay measured the binding of lead and mercury through a decrease in the speed of the DNA functionalised nanoparticles as the DNA aptamer binds with the metals, decreasing the nanoparticle charge. This assay was able to measure the binding of each metal ion through a decrease in the current measured at $-1.60 \mathrm{~V}$. There current-voltage curves are shown in figure 6, repeats are shown in Figure S10. 

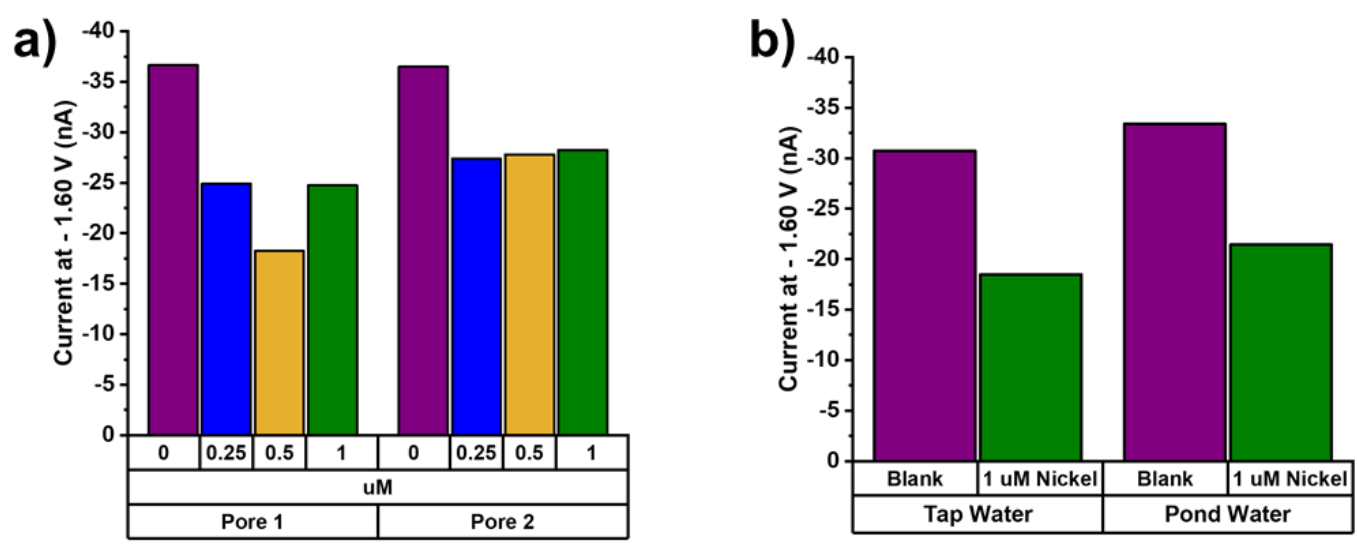

Figure 5: Current observed at $-1.60 \mathrm{~V}$ on a PAAMA coated pore with a PAD functionalised with the peptide aptamer; (a) $0 \mu \mathrm{M}$, purple, $0.25 \mu \mathrm{M}$, blue, $0.5 \mu \mathrm{M}$, yellow and $1 \mu \mathrm{M}$, green, nickel(II) solutions tested on two different pores on two different days, (b) tap water and pond water spiked with, green, and without, purple, $1 \mu \mathrm{M}$ nickel(II). All current-voltage curve data was obtained on NP200s nanopores with $5 \mathrm{mM} \mathrm{KCl}$ electrolyte.

To test the ability of the assay to multiplex metal ions, the three aptamers were functionalised onto one PAD in distinct separate areas, then either solutions containing different mixtures of the metal ions in DI water, or DI water (blank) where dropped onto the PAD. Here chromatography paper was used as it allowed for solutions to be dropped onto the paper rather than requiring incubation within the solution. As previously discussed, chromatography has no inherent charge and has no effect on the pores ability to display ICR. Initial testing indicated the ability of the chromatography PAD to bind with the aptamers post avidin functionalisation and then metal ions, as the current observed at $-1.60 \mathrm{~V}$ was seen to change by $>5 \mathrm{nA}$. Here for clarity, the ICR ratios of PADs with the three different aptamers attached and different metal solutions dropped on are reported in Table 2, repeats are in Table S2. A decrease in ICR ratio indicates binding between aptamer and metal ions. 


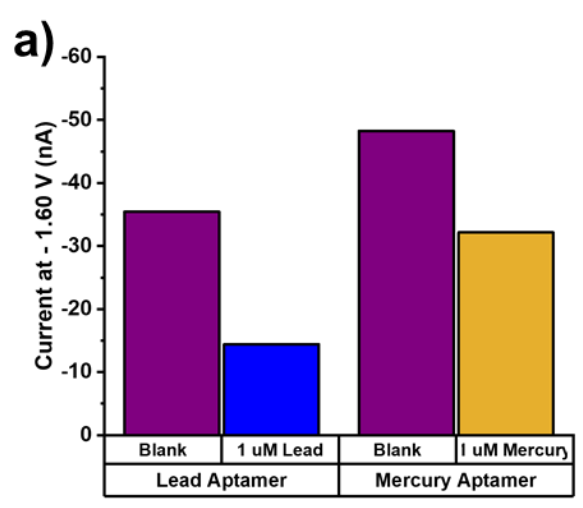

Figure 6: Current observed at $-1.60 \mathrm{~V}$ on a PAAMA coated pore with a PAD functionalised with the lead aptamer and mercury aptamer incubated with, and without, purple, 1 uM Lead(II), blue or mercury(II) yellow, for 30 minutes before being placed on the pore. All current-voltage curve data was obtained on NP200s nanopores with $5 \mathrm{mM} \mathrm{KCl}$ electrolyte.

Table 2: ICR ratios of chromatography PADs functionalised with the three different metal ion aptamers incubated with four different metal ion solution mixtures.

\begin{tabular}{|c|c|c|c|}
\hline \multirow{2}{*}{$\begin{array}{c}\text { Metal } \\
\text { present }\end{array}$} & Target & \multicolumn{2}{|c|}{ ICR Ratio, -1.60 V/1.60 V } \\
\cline { 2 - 4 } & & Blank & Test \\
\hline \multirow{3}{*}{$\begin{array}{c}\mathrm{Hg}^{2+}, \mathrm{Ni}^{2+} \\
\text { and } \mathrm{Pb}^{2+}\end{array}$} & $\mathrm{Hg}^{2+}$ & 21.45 & 16.98 \\
\cline { 2 - 4 } & $\mathrm{Ni}^{2+}$ & 14.86 & 1.72 \\
\cline { 2 - 4 } & $\mathrm{Pb}^{2+}$ & 17.89 & 13.39 \\
\hline \multirow{3}{*}{$\begin{array}{c}\mathrm{Hg}^{2+}, \text { and } \\
\mathrm{Ni}^{2+}\end{array}$} & $\mathrm{Hg}^{2+}$ & 7.27 & 4.71 \\
\cline { 2 - 4 } & $\mathrm{Ni}^{2+}$ & 7.21 & 4.51 \\
\cline { 2 - 4 } & $\mathrm{Pb}^{2+}$ & 2.00 & 1.66 \\
\hline \multirow{3}{*}{$\mathrm{Ni}^{2+}$ and $\mathrm{Pb}^{2+}$} & $\mathrm{Hg}^{2+}$ & 18.56 & 18.46 \\
\cline { 2 - 4 } & $\mathrm{Ni}^{2+}$ & 14.3 & 10.55 \\
\cline { 2 - 4 } & $\mathrm{Pb}^{2+}$ & 18.9 & 13.78 \\
\hline \multirow{2}{*}{$\begin{array}{c}\mathrm{Hg}^{2+} \text { and } \\
\mathrm{Pb}^{2+}\end{array}$} & $\mathrm{Hg}^{2+}$ & 11.5 & 1.88 \\
\cline { 2 - 4 } & $\mathrm{Ni}^{2+}$ & 2.32 & 2.12 \\
\cline { 2 - 4 } & $\mathrm{Pb}^{2+}$ & 13.3 & 10 \\
\hline
\end{tabular}

\section{Conclusions}


Here we present a method that utilises the ICR within a Nanopore to "read" the presence or absence of metal ions in solutions. The binding of nickel(II) to the PAD is measured through a significant decrease in the current observed at $-1.60 \mathrm{~V}$. The assay was shown to work in environmental samples with incubation times of 30 minutes. The assays versatility was demonstrated through its ability to be applied with different DNA aptamers and different metal ion targets. Finally, the assay can be used to detect multiple ions simultaneously through the functionalisation with three different aptamers.

\section{Supporting Information Available}

Supporting Information Available: The following files are available free of charge. Example ICR data runs and replicate experiments of the assays. This material is available free of charge via the internet at http://pubs.acs.org

\section{Author Information}

Corresponding Author

*E-mail: m.platt@lboro.ac.uk.

Notes The authors declare no competing financial interest.

\section{Acknowledgements}

The authors would like to thank Dr B Kralj for his guidance and support and the Nuclear Decommissioning Authority for their funding. 
References

(1) Wang, L.; Peng, X.; Fu, H.; Huang, C.; Li, Y.; Liu, Z. Recent Advances in the Development of Electrochemical Aptasensors for Detection of Heavy Metals in Food. Biosens. Bioelectron. 2020, 147, 111777.

(2) Azimi, A.; Azari, A.; Rezakazemi, M.; Ansarpour, M. Removal of Heavy Metals from Industrial Wastewaters: A Review. ChemBioEng Rev. 2017, 4 (1), 37-59.

(3) Razmi, H.; Dehghanzade, M. Highly Selective and Sensitive Electrochemical Determination of $\mathrm{Ni}(\mathrm{II})$ in Real Samples Based on lon-Imprinted Polymer Technology. Electoanalysis 2020, 32 (1), 198-206.

(4) Chervona, Y.; Arita, A.; Costa, M. Carcinogenic Metals and the Epigenome: Understanding the Effect of Nickel, Arsenic, and Chromium. Metallomics 2012, 4, 619-627.

(5) Mirabi, A.; Shokuhi, A.; Nourani, S. Trends in Analytical Chemistry Application of Modified Magnetic Nanoparticles as a Sorbent for Preconcentration and Determination of Nickel lons in Food and Environmental Water Samples. Trends Anal. Chem. 2015, 74, 146-151.

(6) Kang, J. H.; Lee, S. Y.; Ahn, H. M.; Kim, C. A Novel Colorimetric Chemosensor for the Sequential Detection of $\mathrm{Ni} 2+$ and $\mathrm{CN}-$ in Aqueous Solution. Sensors Actuators B Chem. 2017, 242, 25-34.

(7) Edition, F.; (Who), W. H. O. Guidelines for Drinking-Water Quality. World Health 2011, 1 (3), 104-108.

(8) WHO, W. H. O. Nickel in Drinking-Water. Environ. Heal. 2005, 1-16.

(9) Heena; Kaur, R.; Rani, S.; Malik, A. K.; Kabir, A.; Furton, K. G. Determination of cobalt(II), nickel(II) and palladium(II) lons via Fabric Phase Sorptive Extraction in Combination with High-Performance Liquid Chromatography-UV Detection. Sep. Sci. Technol. 2017, 52 (1), 81-90.

(10) Srivastava, N. K.; Majumder, C. B. Novel Biofiltration Methods for the Treatment of Heavy Metals from Industrial Wastewater. J. Hazard. Mater. 2008, 151 (1), 1-8. 
(11) Fu, F.; Wang, Q. Removal of Heavy Metal lons from Wastewaters: A Review. J. Environ. Manage. 2011, 92 (3), 407-418.

(12) Ferreira, S. L. C.; Dos Santos, W. N. L.; Lemos, V. A. On-Line Preconcentration System for Nickel Determination in Food Samples by Flame Atomic Absorption Spectrometry. Anal. Chim. Acta 2001, 445, 145-151.

(13) Ghaedi, M.; Shokrollahi, A.; Ahmadi, F.; Rajabi, H. R.; Soylak, M. Cloud Point Extraction for the Determination of Copper, Nickel and Cobalt lons in Environmental Samples by Flame Atomic Absorption Spectrometry. J. Hazard. Mater. 2008, 150 (3), 533-540.

(14) Ghaedi, M.; Ahmadi, F.; Shokrollahi, A. Simultaneous Preconcentration and Determination of Copper, Nickel, Cobalt and Lead Ions Content by Flame Atomic Absorption Spectrometry. J. Hazard. Mater. 2007, 142 (1-2), 272-278.

(15) Ohta, K.; Ishida, K.; Itoh, S.; Kaneco, S.; Mizuno, T. Determination of Nickel in Water by Electrothermal Atomic Absorption Spectrometry with Preconcentration on a Tungsten Foil. Mikrochim. Acta 1998, 129 (1-2), 127132.

(16) Milne, A.; Landing, W.; Bizimis, M.; Morton, P. Determination of Mn, Fe, Co, $\mathrm{Ni}, \mathrm{Cu}, \mathrm{Zn}, \mathrm{Cd}$ and $\mathrm{Pb}$ in Seawater Using High Resolution Magnetic Sector Inductively Coupled Mass Spectrometry (HR-ICP-MS). Anal. Chim. Acta 2010, 665 (2), 200-207.

(17) Louie, H.; Wu, M.; Di, P.; Snitch, P.; Chapple, G. Direct Determination of Trace Elements in Sea-Water Using Reaction Cell Inductively Coupled Plasma Mass Spectrometry. J. Anal. At. Spectrom. 2002, 17 (6), 587-591.

(18) Park, C. J.; Yim, S. a. Determination of Nickel in Water Samples by Isotope Dilution Inductively Coupled Plasma Mass Spectrometry with Sample Introduction by Carbonyl Vapor Generation. J. Anal. At. Spectrom. 1999, 14 (7), 1061-1065.

(19) Wang, J.; Hansen, E. H. On-Line Sample-Pre-Treatment Schemes for TraceLevel Determinations of Metals by Coupling Flow Injection or Sequential Injection with ICP-MS. TrAC - Trends Anal. Chem. 2003, 22 (11), 836-846. 
(20) Anthemidis, A. N.; Miró, M. Recent Developments in Flow Injection/sequential Injection Liquid-Liquid Extraction for Atomic Spectrometric Determination of Metals and Metalloids. Appl. Spectrosc. Rev. 2009, 44 (2), 140-167.

(21) De Jesus, A.; Zmozinski, A. V.; Barbará, J. A.; Vale, M. G. R.; Silva, M. M. Determination of Calcium and Magnesium in Biodiesel by Flame Atomic Absorption Spectrometry Using Microemulsions as Sample Preparation. Energy and Fuels 2010, 24 (3), 2109-2112.

(22) Dimpe, K. M.; Ngila, J. C.; Nomngongo, P. N. Preparation and Application of a Tyre-Based Activated Carbon Solid Phase Extraction of Heavy Metals in Wastewater Samples. Phys. Chem. Earth 2018, 105 (August 2017), 161-169.

(23) Xing, G.; Sardar, M. R.; Lin, B.; Lin, J. M. Analysis of Trace Metals in Water Samples Using NOBIAS Chelate Resins by HPLC and ICP-MS. Talanta 2019, 204 (February), 50-56.

(24) Tomar, P. K.; Chandra, S.; Malik, A.; Kumar, A. Nickel Analysis in Real Samples by Ni2+selective PVC Membrane Electrode Based on a New Schiff Base. Mater. Sci. Eng. C 2013, 33 (8), 4978-4984.

(25) McGhee, C. E.; Loh, K. Y.; Lu, Y. DNAzyme Sensors for Detection of Metal lons in the Environment and Imaging Them in Living Cells. Curr. Opin. Biotechnol. 2017, 45, 191-201.

(26) Subramanian, K. S. Determination of Metals in Biofluids and Tissues: Sample Preparation Methods for Atomic Spectroscopic Techniques. Spectrochim. Acta - Part B At. Spectrosc. 1996, 51 (3 PART B), 291-319.

(27) Feng, J.; Jin, W.; Huang, P.; Wu, F. Highly Selective Colorimetric Detection of $\mathrm{Ni2}+$ Using Silver Nanoparticles Cofunctionalized with Adenosine Monophosphate and Sodium Dodecyl Sulfonate. J. Nanoparticle Res. 2017, 19 (9), 306.

(28) Shibata, H.; Hiruta, Y.; Citterio, D. Fully Inkjet-Printed Distance-Based Paper Microfluidic Devices for Colorimetric Calcium Determination Using lonSelective Optodes. Analyst 2019, 144 (4), 1178-1186. 
(29) Shrivas, K.; Maji, P.; Dewangan, K. Onsite-Detection of Barium and Nickel from River, Pond and Tap Water Samples Using Gold Nanoparticles as a Chemical Sensor. Spectrochim. Acta - Part A Mol. Biomol. Spectrosc. 2017, 173, 630-636.

(30) Salins, L. L.; Goldsmith, E. S.; Ensor, M. C.; Daunert, S. A FluorescenceBased Sensing System for the Environmental Monitoring of Nickel Using the Nickel Binding Protein from Escherichia Coli. Anal. Bioanal. Chem. 2002, 372 (1), 174-180.

(31) Lv, X. L.; Luo, S. Z. A Fluorescence Chemosensor Based on Peptidase for Detecting nickel(II) with High Selectivity and High Sensitivity. Anal. Bioanal. Chem. 2012, 402 (9), 2999-3002.

(32) Miyawaki, A.; Llopis, J.; Heim, R.; Michael McCaffery, J.; Adams, J. A.; Ikura, M.; Tsien, R. Y. Fluorescent Indicators for Ca2+ Based on Green Fluorescent Proteins and Calmodulin. Nature 1997, 388 (6645), 882-887.

(33) Yu, T.; Zhou, W.; Liu, J. Screening of DNAzyme Mutants for Highly Sensitive and Selective Detection of Calcium in Milk. Anal. Methods 2018, 10 (15), 1740-1746.

(34) Li, L.; Ma, X.; Dong, W.; Miao, P.; Tang, Y. Electrochemical Determination of Ca 2+ Based On Recycling Formation of Highly Selective DNAzyme and Gold Nanoparticle-Mediated Amplification. Bioconjug. Chem. 2018, 29 (4), 10211024.

(35) Ferancová, A.; Hattuniemi, M. K.; Sesay, A. M.; Räty, J. P.; Virtanen, V. T. Rapid and Direct Electrochemical Determination of $\mathrm{Ni}(\mathrm{II})$ in Industrial Discharge Water. J. Hazard. Mater. 2016, 306, 50-57.

(36) Gong, M. M.; Zhang, P.; Macdonald, B. D.; Sinton, D. Nanoporous Membranes Enable Concentration and Transport in Fully Wet Paper-Based Assays. Anal. Chem. 2014, 86 (16), 8090-8097.

(37) Hong, S.; Kwak, R.; Kim, W. Paper-Based Flow Fractionation System Applicable to Preconcentration and Field-Flow Separation. Anal. Chem. 2016, 88 (3), 1682-1687. 
(38) Gu, L.; Braha, O.; Conlan, S.; Cheley, S.; Bayley, H. Stochastic Sensing of Organic Analytes by a Pore-Forming Protein Containing a Molecular Adapter. Nature 1999, 398, 686-690.

(39) Bayley, H.; Cremer, P. S. Stochastic Sensors Inspired by Biology. Nature 2001, 413 (6852), 226-230.

(40) Wang, G.; Wang, L.; Han, Y.; Zhou, S.; Guan, X. Nanopore Detection of Copper lons Using a Polyhistidine Probe. Biosens. Bioelectron. 2014, 53, 453458.

(41) Wang, G.; Zhao, Q.; Kang, X.; Guan, X. Probing Mercury(II) - DNA Interactions by Nanopore Stochastic Sensing. J. Phys. Chem. B 2013, 117 (3), 4763-4769.

(42) Roozbahani, G. M.; Chen, X.; Zhang, Y.; Xie, R.; Ma, R.; Li, D.; Li, H.; Guan, X. Peptide-Mediated Nanopore Detection of Uranyl Ions in Aqueous Media. ACS Sensors 2017, 2 (5), 703-709.

(43) Liu, G.; Zhang, L.; Dong, D.; Liu, Y.; Li, J. A Label-Free DNAzyme-Based Nanopore Biosensor for Highly Sensitive and Selective Lead Ion Detection. Anal. Methods 2016, 8 (39), 7040-7046.

(44) Papp, S.; Gyula, J.; Gyurcs, E. Ion-Selective Electrodes Based on Hydrophilic lonophore-Modified Nanopores. Angew. Chemie - Int. Ed. 2018, 57 (17), 4752-4755.

(45) Müller, L. K.; Duznovic, I.; Tietze, D.; Weber, W.; Ali, M.; Stein, V.; Ensinger, W. Ultrasensitive and Selective Copper (II) Detection: Introducing a Bioinspired and Robust Sensor. Chem. - A Eur. J. 2020, 1-11.

(46) Mayne, L.; Lin, C. Y.; Christie, S. D. R.; Siwy, Z. S.; Platt, M. The Design and Characterization of Multifunctional Aptamer Nanopore Sensors. ACS Nano 2018, 12 (5), 4844-4852.

(47) Mayne, L. J.; Christie, S. D. R.; Platt, M. A Tunable Nanopore Sensor for the Detection of Metal lons Using Translocation Velocity and Biphasic Pulses. Nanoscale 2016, 8 (45). 
(48) Heaton, I.; Platt, M. Peptide Nanocarriers for Detection of Heavy Metal lons Using Resistive Pulse Sensing. Anal. Chem. 2019, 91 (17), 11291-11296.

(49) Cao, L.; Guo, W.; Wang, Y.; Jiang, L. Concentration-Gradient-Dependent Ion Current Rectification in Charged Conical Nanopores. Langmuir 2012, 28 (4), 2194-2199.

(50) White, H. S.; Bund, A. Ion Current Rectification at Nanopores in Glass Membranes. Langmuir 2008, 24 (5), 2212-2218.

(51) Yusko, E. C.; An, R.; Mayer, M. Electroosmotic Flow Can Generate Ion Current Rectification in Nano- and Micropores. ACS Nano 2010, 4 (1), 477487.

(52) Cheng, L.; Guo, L. J. Ionic Current Rectification, Breakdown, and Switching in Heterogeneous Oxide Nanofluidic Devices. ACS Nano 2009, 3 (3), 575-584.

(53) Yeh, L.; Hughes, C.; Zeng, Z.; Qian, S. Tuning Ion Transport and Selectivity by a Salt Gradient in a Charged Nanopore. Anal. Chem. 2014, 86 (5), 2681-2686.

(54) Blundell, E. L. C. J.; Mayne, L. J.; Lickorish, M.; Christie, S. D. R.; Platt, M. Protein Detection Using Tunable Pores: Resistive Pulses and Current Rectification. Faraday Discuss. 2016, 193 (193), 487-505.

(55) Lin, C.; Yeh, L.; Siwy, Z. S. Voltage-Induced Modulation of Ionic Concentrations and lon Current Rectification in Mesopores with Highly Charged Pore Walls. Jounral Phys. Chem. Lett. 2018, 9, 393-398.

(56) Blundell, E. L. C. J.; Vogel, R.; Platt, M. Particle-by-Particle Charge Analysis of DNA-Modified Nanoparticles Using Tunable Resistive Pulse Sensing. Langmuir 2016, 32 (4), 1082-1090.

(57) Maugi, R.; Salkenova, Z.; Platt, M. Incorporating Peptide Aptamers into Resistive Pulse Sensing. Med. Devices Sensors 2020, 3 (1), 1-7.

(58) Tan, S. yin; Perry, D.; Unwin, P. R. Double Layer Effects in Voltammetric Measurements with Scanning Electrochemical Microscopy (SECM). J. Electroanal. Chem. 2018, 819 (October 2017), 240-250. 
(59) Chen, B.; Perry, D.; Page, A.; Kang, M.; Unwin, P. R. Scanning Ion Conductance Microscopy: Quantitative Nanopipette Delivery-Substrate Electrode Collection Measurements and Mapping. Anal. Chem. 2019, 91 (3), 2516-2524.

(60) Lucas, R. A.; Lin, C. Y.; Siwy, Z. S. Electrokinetic Phenomena in Organic Solvents. J. Phys. Chem. B 2019, 123 (28), 6123-6131.

(61) Leong, I. W.; Tsutsui, M.; Murayama, S.; He, Y.; Taniguchi, M. ElectroosmosisDriven Nanofluidic Diodes. J. Phys. Chem. B 2020, 124 (32), 7086-7092.

(62) Ali, M.; Nasir, S.; Ensinger, W. Bioconjugation-Induced lonic Current Rectification in Aptamer-Modified Single Cylindrical Nanopores. Chem. Commun. 2015, 51 (16), 3454-3457.

(63) Ali, M.; Nasir, S.; Ensinger, W. Stereoselective Detection of Amino Acids with Protein-Modified Single Asymmetric Nanopores. Electrochim. Acta 2016, 215, 231-237.

(64) Ali, M.; Ramirez, P.; Nguyen, H. Q.; Nasir, S.; Cervera, J.; Mafe, S.; Al, A. L. I. E. T. Single Cigar-Shaped Nanopores Functionalized with Amphoteric Amino Acid Chains : Experimental and Theoretical Characterization. ACS Nano 2012, $6(4), 3631-3640$.

(65) Hsu, J.; Lin, C.; Siwy, Z. S. Tunable Current Rectification and Selectivity Demonstrated in Nano Fluidic Diodes through Kinetic Functionalization'. Jounral Phys. Chem. Lett. 2020, 11, 60-66.

(66) Lepoitevin, M.; Nguyen, G.; Bechelany, M.; Balanzat, E.; Janot, J.; Balme, S. Combining a Sensor and a pH-Gated Nanopore Based on an Avidin-biotin System. Chem. Commun. 2015, 51, 5994-5997.

(67) Karnik, R.; Duan, C.; Castelino, K.; Daiguji, H.; Majumdar, A. Rectification of Ionic Current in a Nanofluidic Diode. Nano Lett. 2007, 7 (3), 547-551.

(68) Gao, R.; Ying, Y.; Yan, B.; Iqbal, P.; Preece, J. A. Ultrasensitive Determination of Mercury ( II ) Using Glass Nanopores Functionalized with Macrocyclic Dioxotetraamines. 2016, 491-495. 
(69) Wang, H.; Hou, S.; Wang, Q.; Wang, Z.; Fan, X.; Zhai, J. Dual-Response for $\mathrm{Hg} 2+$ and $\mathrm{Ag}+$ lons Based on Biomimetic Funnel-Shaped Alumina Nanochannels. J. Mater. Chem. B 2015, 3, 1699-1705.

(70) Chen, L.; He, H.; Xu, X.; Jin, Y. Single Glass Nanopore-Based Regenerable Sensing Platforms with Anon-Immobilized Polyglutamic Acid Probe for Selective Detection of Cupric Ions. Anal. Chim. Acta 2015, 889, 98-105.

(71) Actis, P.; McDonald, A.; Beeler, D.; Vilozny, B.; Millhauser, G.; Pourmand, N. Copper Sensing with a Prion Protein Modified Nanopipette. RSC Adv. 2012, 2 (31), 11638-11640.

(72) Sa, N.; Fu, Y.; Baker, L. A. Reversible Cobalt Ion Binding to ImidazoleModified Nanopipettes. Anal. Chem. 2010, 82 (24), 9963-9966.

(73) Přistoupil, T. I.; Kramlová, M.; Štěrbíková, J. On the Mechanism of Adsorption of Proteins to Nitrocellulose in Membrane Chromatography. J. Chromatogr. A 1969, 42 (C), 367-375.

(74) European Commission. Commission Directive 2003/40/EC of 16 May 2003 Establishing the List, Concentration Limits and Labelling Requirements for the Constituents of Natural Mineral Waters and the Conditions for Using OzoneEnriched Air for the Treatment of Natural Mineral Water. Off. J. Eur. Union 2003, 126, 34-39. 

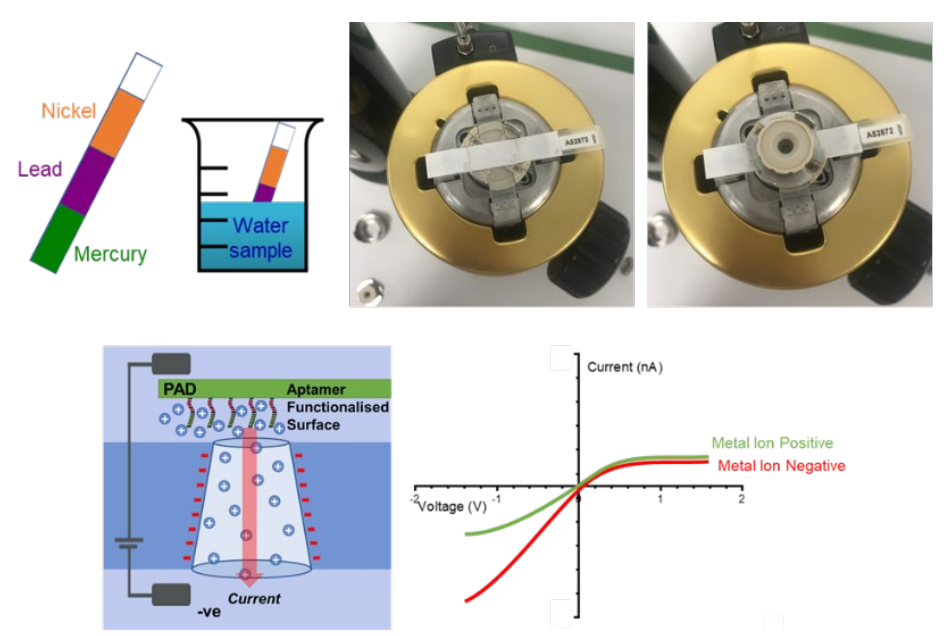

TOC only 